\title{
Effects of enzymatic modification of soybean protein on the pasting and rheological profile of starch-protein systems
}

\author{
Pablo D. Ribotta ${ }^{1,2}$ and Cristina M. Rosell ${ }^{1}$ \\ ${ }^{1}$ Cereal Group, Institute of Agrochemistry and Food Technology (IATA-CSIC), Burjassot, \\ Spain \\ ${ }^{2}$ Universidad Nacional de Córdoba, Córdoba, Argentina.
}

Corresponding Author: Ribotta, Pablo Daniel <pribotta@agro.unc.edu.ar>

Keywords: starch, soybean protein, enzymatic modification

\begin{abstract}
Reformulation of traditional food systems to introduce new ingredients may change their structure and perceived texture. Interactions between proteins and starch during processing can markedly influence starch gel network structure and rheological profile. The present work aimed to study the effects of soybean protein and the products of enzymatic modification on the pasting and rheological profile of corn and cassava starch. The behaviour of those protein enriched gels during storage was also assessed. Soybean protein isolate (SPI) was incubated with endopeptidase (AL) or food grade microbial transglutaminase (TG). Pasting and rheological behaviour, water retention capacity and structure of protein- and hydrolysed protein-starch gels were analyzed. Protein incorporation increased the viscosity of starch suspension during and after heating. SPImodified proteins increased peak viscosity. Only the structural modifications brought by TG on SPI increased the final viscosity during starch pasting and the storage modulus $\left(\mathrm{G}^{\prime}\right)$. This modulus $\left(\mathrm{G}^{\prime}\right)$ of the gelled systems decreased with the addition of AL-treated protein isolate. Light and fluorescence microscopy showed that SPI formed a continuous phase, like a network, in the gelled system. Different network structures and rheological properties can be obtained when SPI are modified by protease and transglutaminase enzymes, which may be very useful for designing new food products.
\end{abstract}

\section{INTRODUCTION}

Reformulation of traditional food systems to introduce new ingredients may change their structure and perceived texture, since products result from interactions between different components. The development of protein enriched products has focussed the attention of food technologist when aimed at the design of innovative food with improved nutritional properties. Interactions between proteins and starch during processing can markedly influence starch gel network structure and rheological profile. 
It is well known that protein yield per hectare from soybean is the highest among all other animal or plant sources. No other source has as much protein with good nutritional quality due to its amino acid composition and biological availability. Soybean is rich in lysine but deficient in methionine and cysteine. Soybean thus can serve, as a complementary protein for cereals that are deficient in lysine and rich in methionine [1].

Functionalities of commercially available soybean proteins are further lowered as a result of denaturation during the prior defatting process. Ribotta et al [2] analyzed the influence of soybean protein on physical and rheological properties of wheat starch and the interactions among them. The main results showed that soybean protein isolate increased the viscosity of starch suspension during and after heating, and pastes and gels with soybean protein presented a weaker structure than non-protein products. The negative changes of the inclusion of soybean protein in starch systems could be overcome or decrease by enzymatic modification of proteins. Improvement of soybean protein functional properties, therefore, is highly desirable so that they may successfully perform specific functions in food applications. The modifications of proteins by enzymatic methods have been extensively studied and have been shown to be very powerful tools for improving the functional properties of these macromolecules.

Food proteins could be hydrolysed to improve nutritional and functional properties and texture characteristics, to remove odour, flavour, and toxic or antinutritive components [3, $4,5]$. Partial hydrolysis reduces the molecular weight and increases the solubility in water over the entire $\mathrm{pH}$, enhancing both foaming capacity and stability [1]. Alcalase is a serine alkaline protease produced by a selected strain of Bacillus licheniformis. Its main enzyme component, subtilisin Carlsberg (also called subtilisin, subtilisin A, subtilopeptidase A, and Alcalase Novo). The enzyme has a pH optimum for activity between $\mathrm{pH} 8$ and 9 and broad $\mathrm{pH}$ stability [6]. Adler-Nissen [7] revealed that Alcalase has a broad specificity but mainly cleaves on the carboxyl side of hydrophobic amino acids.

The improvements in the functional properties of food proteins by cross-linking could increase their application scope in the food industry. Transglutaminase (TG, proteinglutamine $\gamma$-glutamyltransferase, EC 2.3.2.13) catalyses an acyl-transfer reaction between the $\gamma$-carboxyamide group of peptide-bound glutamine residues (acyl donors) and a variety of primary amines (acyl acceptors), including the $\varepsilon$-amino group of lysine residues. Transglutaminase can modify proteins by means of amine incorporation, crosslinking and deamidation [8]. The most dominant reaction catalyzed by transglutaminase is the covalent crosslinking between an $\varepsilon$-amino group on protein bound lysine residues and a $\gamma$ carboxyamide group on protein-bound glutamine residues [9]. The enzyme has a $\mathrm{pH}$ optimum range for activity between $\mathrm{pH} 5$ and 8 (Data Sheet provided by Ajinomoto Co. Inc.). Cross-linking of food protein by transglutaminase from microbial sources has been extensively studied. This enzymatic cross-linking has been proved to be effective in improving some functional properties of soybean proteins as hydration and gelling ability, emulsifying or foaming properties of soybean protein digests, and thermal properties [10, 11], and gelling ability $[12,13,14,15]$. This strategy has been applied for developing protein enriched gluten free breads, obtaining protein networks with good features for breadmaking performance [16].

The present work aimed to study the effects of soybean protein enzymatic modification by protease or transglutaminase on the pasting and rheological profile of corn and cassava 
starches. Microscopic studies were also carried out for explaining the impact of enzyme treated soybean proteins on the starchy structures.

\section{MATERIALS AND METHODS}

\section{Materials}

Native corn (123 $\mathrm{g} \mathrm{kg}^{-1}$ moisture, $4.1 \mathrm{~g} \mathrm{~kg}^{-1}$ protein, dry basis) and cassava (156 g kg moisture, $4.2 \mathrm{~g} \mathrm{~kg}^{-1}$ protein, dry basis) starches were purchased in the local market (Señor de Sipan, Argentina). Commercial soybean protein isolate (SPI) was obtained from Trades SA (Barcelona, Spain) and had moisture, protein, lipid, and ash contents of $69 \mathrm{~g} \mathrm{~kg}^{-1}, 808 \mathrm{~g}$ $\mathrm{kg}^{-1}, 2 \mathrm{~g} \mathrm{~kg}^{-1}$ and $36 \mathrm{~g} \mathrm{~kg}^{-1}$ (dry basis), respectively. Food grade microbial transglutaminase (TG) from Streptomyces spp. from Ajinomoto Co. Inc. (Tokyo, Japan) (100 units $\mathrm{g}^{-1}$ ) was kindly supplied by Apliena, SA (Terrasa, Barcelona, Spain). Protease from Bacillus licheniformis (Alcalase ${ }^{\circledR}$ 2.4 L FG) (AL) was kindly donated by Novozymes (Madrid, Spain.). All reagents in this study were of analytical grade.

\section{Alcalase and transglutaminase treatments of soybean protein isolates}

Soybean proteins $(1.32 \mathrm{~g})$ were dispersed in $20 \mathrm{~mL}$ of distilled water. The $\mathrm{pH}$ of the suspension was adjusted to $\sim 6.5$. Preliminary assays were conducted to optimize the incubation time and enzyme amount to produce extensive enzymatic reaction followed by electrophoresis studies. Transglutaminase ( $0.83 \mathrm{TG}$ units per gram soybean protein isolate) or $30 \mu \mathrm{L}$ of Alcalase (49.1 mAU per gram soybean protein isolate) were added to the protein suspensions. The suspensions were incubated for 5 hours at $35^{\circ} \mathrm{C}$. The enzyme was inactivated by keeping the mixture in boiling water bath for $10 \mathrm{~min}$ and the slurry was cooled down to room temperature. Non-enzimatically treated ISP followed the same procedure (incubation for 5 hours at $35^{\circ} \mathrm{C}$ and heating for $10 \mathrm{~min}$ ) than the enzyme treated samples except that no enzyme was added.

\section{Protein and peptide solubility}

The digested mixtures were centrifuged $(4,400 \mathrm{x} \mathrm{g}$, for $15 \mathrm{~min}$ ) to precipitate insoluble protein. The supernatants were analyzed for nitrogen content (micro-Kjeldahl method AACC 46-13). The reaction progress was estimated by measuring the nitrogen content of the supernatants, which was able to keep soluble in a solution of $10 \%$ trichloroacetic acid (TCA) as showed by Kong et al. [17]. Each determination was done, at least, in duplicate.

\section{Electrophoresis.}

The digested mixtures were centrifuged $(4,400 \mathrm{xg}$, for $15 \mathrm{~min})$ to precipitate insoluble protein. The supernatants were analyzed by sodium dodecyl sulphate polyacrylamide gel electrophoresis (SDS-PAGE). It was performed using gels of $\mathrm{T}=12 \%$ and $\mathrm{C}=2.7 \%$. The gels were $0.75-\mathrm{mm}$ thick and consisted of a $2-\mathrm{cm}$ stacking gel and an $8-\mathrm{cm}$ running gel. The electrophoresis was conducted at a constant voltage of $150 \mathrm{~V}$ until the front reached the end of the gel (in approximately $90 \mathrm{~min}$ ). A Mini Protean II Slab Cell (Bio-Rad Laboratories, Richmond, CA) was used. MW standards were obtained from Bio-Rad (Broad range, BioRad Laboratories, Hercules, USA). Equal volume of each extract were applied to the electrophoresis gels for quantitative comparisons. The gels were stained with $0.25 \%$ 
Coomassie Brilliant Blue $\mathrm{R}$ in methanol/water/acetic acid (4:5:1 v/v) and were distained in the same solvent.

\section{Viscosity profile during the thermo-mechanical process}

A rapid visco-analyser (RVA) instrument (Newport Scientific, Australia) was utilized to prepare the samples and follow the apparent viscosity profile of the samples as a function of temperature and time. Corn or cassava starch $(1.32 \mathrm{~g})$ and the slurry from enzymatic treatment (1.32 $\mathrm{g}$ of SPI and $20 \mathrm{~mL}$ of water, $\mathrm{pH} 6.5)$ and $5 \mathrm{~mL}$ of water (after rinse the protein slurry) were place inside the aluminium canister and the $\mathrm{pH}$ was again adjusted to 6.5. Mixtures had $4.8 \%(\mathrm{w} / \mathrm{w})$ starch and $4.8 \%(\mathrm{w} / \mathrm{w})$ SPI. Corn and cassava starch were also analyzed by dispersing 1.32 grams of starch with $25 \mathrm{~mL}$ of distilled water $(5.0 \% \mathrm{w} / \mathrm{w}$ starch). RVA corn starch Pasting Method was applied as follows: automatic stirring action was set at $960 \mathrm{rpm}$ for $10 \mathrm{~s}$ and then slowed down to $160 \mathrm{rpm}$. The temperature of the sample was equilibrated at $50{ }^{\circ} \mathrm{C}$, heated to $95^{\circ} \mathrm{C}$ for $4 \min 42 \mathrm{~s}$, held at $95{ }^{\circ} \mathrm{C}$ for $3 \mathrm{~min}$, cooled to $50{ }^{\circ} \mathrm{C}$ over $3 \mathrm{~min} 42 \mathrm{~s}$, and then held at $50^{\circ} \mathrm{C}$ for $2 \mathrm{~min}$. Viscosity and temperature were recorded over time; data gathering and analysis were performed using Thermocline for Windows software, provided by the instrument manufacturer. Pasting temperature, peak viscosity, final viscosity, breakdown, and setback were obtained from the viscograms.

After the measure of viscosity profile, the suspension was poured while hot $\left(50^{\circ} \mathrm{C}\right)$ into polypropylene tubes, $30 \mathrm{~mm}$ diameter, cooled to room temperature $\left(25^{\circ} \mathrm{C}\right)$ and kept for $4 \mathrm{~h}$ at that temperature. The samples were stored at $25^{\circ} \mathrm{C}$ and at $4{ }^{\circ} \mathrm{C}$ before analyzing the rheological properties and syneresis respectively. Each analysis was done in duplicate.

\section{Rheological measurements}

After the thermo-mechanical preparation process, the samples were kept at $25^{\circ} \mathrm{C}$ for $24 \mathrm{~h}$. The viscoelastic behaviour of each sample was measured in duplicate. Measurements were carried out in a controlled stress rheometer RheoStress 1 (Thermo Haake, Germany), using serrated plate-plate geometry of $60 \mathrm{~mm}$ diameter and $0.5 \mathrm{~mm}$ gap, at a temperature of 25 ${ }^{\circ} \mathrm{C}$. Samples were carefully poured into the lower plate to minimize the possible breakdown of the gel network. After descending the upper plate, samples were allowed to rest for 3 min. Fresh sample was loaded for each measurement. In order to determine the linear viscoelastic region, strain sweeps $(0.01-100 \%)$ were run at $1 \mathrm{~Hz}$. The frequency sweeps were then performed at $0.04 \%$ over a frequency range of 0.01 to $10 \mathrm{~Hz}$ and the values of the storage modulus $\left(\mathrm{G}^{\prime}\right)$, the loss modulus $\left(\mathrm{G}^{\prime \prime}\right)$, the loss tangent $(\tan \delta)$, as a function of frequency, were calculated using the Rheowin Pro software (version 2.93, Thermo Haake). Two fresh samples of each gel lot were measured and gels were elaborated in duplicate to ensure reliable results.

\section{Syneresis}

Syneresis was measured by a centrifugation test [2] using a Beckman J2-MI centrifuge (Beckman Instruments, USA). Starch and starch-soybean protein dispersions (prepared as described previously) ( $\sim 15 \mathrm{~g})$ were placed into $50 \mathrm{~mL}$ centrifuge tubes while they were hot and stored seven days at $4{ }^{\circ} \mathrm{C}$. After storage, the gels were tempered at $25^{\circ} \mathrm{C}$ for $2 \mathrm{~h}$ and centrifuged at $1,500 \mathrm{x}$ g for $15 \mathrm{~min}$ at $25^{\circ} \mathrm{C}$. After centrifugation the free water was 
separated, weighed and expressed as percentage of the total water present in the gel. Measurements were the mean of three repetitions for each duplicated gel.

\section{Bright field and fluorescence microscopy}

The gelatinized starch and starch/protein gels were poured and spread out onto microscope slide and the samples were dehydrated using pure ethanol and hot air. Starch was detected using iodine solution, and proteins were detected with Ponceau Red. The dry samples were stained with iodine $(0.2 \% \mathrm{w} / \mathrm{v}$ iodine and $2 \% \mathrm{w} / \mathrm{v}$ potassium iodide $)$ and Ponceau $2 \mathrm{R}(0.2$ $\% \mathrm{w} / \mathrm{v}$ Ponceau $2 \mathrm{R}$ in $50 \%$ ethanol containing $0.18 \% \mathrm{v} / \mathrm{v}$ of $0.5 \mathrm{M} \mathrm{H}_{2} \mathrm{SO}_{4}$ ) solutions. After each staining, sections were rinsed in distilled water, followed by a wash in $70 \%(\mathrm{v} / \mathrm{v})$ ethanol and finally washed in absolute ethanol. The distribution of protein and starch in the sample was observed using a light/fluorescence Nikon Eclipse 90i microscope (IZASA, Spain).

\section{Statistical analysis}

The data obtained were statistically treated using analysis of variance while the means were compared by the LSD Fisher test at a significance level of 0.05 using Statgraphics Plus software (v2.01).

\section{RESULTS AND DISCUSSION}

\section{Alcalase and transglutaminase treatments}

A significant reduction of nitrogen solubility was found when SPI was treated with TG, from $2.84 \pm 0.00 \mathrm{mg} / \mathrm{mL}$ (non-treated proteins) to $2.18 \pm 0.13 \mathrm{mg} / \mathrm{mL}$ (TG-treated proteins), which represents a decrease of $23 \%$ protein solubility. SDS-PAGE protein patterns are shown in Figure 1. TG-treated SPI (line 2) showed an evident increase in intensity at the top of the running gel and a slight reduction of some band areas (arrows) as compared with the non-treated protein profile (lane 1). This result confirms the formation of protein polymers of higher molecular weight with a concomitant disappearance of the lowermolecular weight polypeptides. The reduction of nitrogen solubility was associated to the increase in molecular weight of these proteins. Similar results were reported by Tang et al. [15] and Marco et al [18] when soybean protein and SPI-rice flour blends, respectively, were treated with TG. Conversely, Walsh et al. [14] did not find differences in solubility of TG-treated SPI between $\mathrm{pH} 6.5-8$, likely due to the solubility behaviour was $\mathrm{pH}$ dependent. The discrepancy could arise from the production process of the protein isolate, since it may cause physical and chemical changes and, therefore, they may affect the solubility of the proteins [19].

The nitrogen content on 10\%-TCA supernatants increased from $0.163 \pm 0.02 \mathrm{mg} / \mathrm{mL}$ (non-treated proteins) to $1.06 \pm 0.13 \mathrm{mg} / \mathrm{mL}$ (AL-treated protein). The dramatic increase of peptides as consequence of hydrolytic activity of protease was confirmed by SDS-PAGE pattern of Al-treated SPI. It showed a total disappearance of bands along the running gel and an increase of low molecular weight bands (Figura 1, lane 3).

\section{Starch pasting profile}


Figure 2 shows the pasting profile of cassava (T) and corn (C) starches and their combinations with treated and non-treated SPI.

When starch granules are heated above the gelatinization temperature in the presence of water, the starch granules absorb water and swell, resulting in an increase in viscosity. The temperature at the onset of this rise in the viscosity can be considered as the pasting temperature (PT) in the RVA. The viscosity of the paste increases to the point where the number of swollen-intact starch granules is maximum, this point is named peak viscosity $(\mathrm{PV})$ and it is considered to be indicative of water-binding capacity. Swelling of granules, accompanied by leaching of amylose, increases the viscosity, while granules may rupture during further heating, resulting in a decrease of viscosity. During the holding period at 95 ${ }^{\circ} \mathrm{C}$, the sample is subjected to mechanical shear stress, which usually leads to further disruption of starch granules and amylose leaching. Leached-out amylose molecules are more or less aligned in the direction of flow, which contributes to the breakdown (BD) in viscosity. As the sample is subsequently cooled down to $50^{\circ} \mathrm{C}$, reordering of amylose chains results in an increased in viscosity until a gel is formed, which is defined as setback (SB). This parameter is related to the retrogradation of the amylose chains. The viscosity at the end of the test is defined as final viscosity (FV).

Cassava starch presented lower pasting temperature (TP) but higher peak viscosity (PV) and final viscosity (FV) than corn starch (Table 1). The lower pasting temperature and rapid rise in viscosity during heating of cassava starch compared to corn starch indicates weaker granular structure, besides Peak viscosity is indicative of water binding capacity, so eassava starch showed better water binding properties than corn starch. Moreover, cassava starch showed superior thickening properties, as indicated the higher FV, than corn starch. however corn starch was more stable to breakdown in viscosity than cassava starch paste. The setback values showed higher retrogradation rate in cassava starch dispersion than in corn starch.

Proteins could affect the gelatinization process in different ways depending on their ability to retain water and their interaction capacity with the starch molecules and surface granules. The pasting temperatures of corn starch-protein mixtures were lower than corn paste (Table 1). Similar results were reported by Goel et al [20], who studied the effect of casein and casein hydrolysates on corn starch gelatinization. On the other hand, mixtures of cassava starch and proteins showed an increase of pasting temperature relative to cassava starch, but a two steps increase was detected during heating. Likely, the viscosity pattern observed in the presence of SPI might be due to the thermal induced gelation of the proteins that occurs after aggregation of the protein polymeric chains on the viscosity increase of starches during heating [21]. The addition of SPI increased the viscosity of starch suspension during and after the heating process. The increase of viscosity during cooling or setback, usually related to the crystallization of the amylose chains when starches are studied, could be affected by the reorganization of the denatured proteins from the protein isolates [11]. During heating, at the same time that water is absorbed, material is leached out from the starch granules. This material is largely amylose, although amylopectin and intermediate material (less branched than amylopectin) are present, the amount of leached material depended on the starch type, the shearing force and the pasting conditions [22]. These researchers also described the gelatinized starch suspension as a composite material composed of a dispersed phase (starch granules) in a continuous polymer solution 
(amylose/amylopectin). The rheological properties of such system depend on the properties and the ratio of the components of the continuous phase, the interaction between them and between the dispersed phase and the matrix. Proteins contain many hydrophilic groups which are capable of forming crosslinks with starch molecules and starch granules. These crosslinks may be responsible for their higher paste viscosity as compared to a starch paste. It is also possible that the starch-protein interactions affected adhesion between phases [2, 20]. Simutaneouly, the effective concentration of starch in the continuous phase, as a consequence of the hydration and solubilization of soybean protein, could increase paste viscosity. Lim and Narsimhan [23] showed that soybean proteins increased pasting temperature and overall viscosity of soybean protein/starch/high fructose corn syrup pastes, and they suggested that this trend could be due to an increase in the concentration of solid contents resulting from the addition of soybean proteins, and/or through self aggregation of soybean globulins.

Alcalase- and transglutaminase-treated proteins produced a higher increment of peak viscosity than non-treated proteins (Table 1), being the highest value induced by TG. The addition of AL-treated SPI decreased FV related to non-treated SPI incorporation. On the other hand, TG-treated protein increased $(\mathrm{p}<0.05)$ both PV and FV of starch pastes relative to non-treated soybean proteins.

Proteins subjected to different mode of enzymatic modifications might have different surface characteristics, and consequently, diverse starch- and water-interaction behaviors. These differences between non-treated and enzyme-treated proteins could be attributed to dissimilar ability to interact with gelatinized starch components and to the changes on the protein solubility and water retention capacity.

By the time peak viscosity is reached, granules have absorbed water and swelled. With continued stirring, the disruption and fragmentation of more granules occur, causing a further decrease in viscosity (breakdown). Breakdown of corn starch was decreased by the incorporation of non-treated and TG-treated proteins. On the other hand, breakdown of cassava starch was increased by the incorporation of non-treated and TG-treated proteins. These results indicated structural differences of the hydrated granules from corn and cassava. The decrease of viscosity was improved (much more higher compared to TG- or non-treated protein) by alcalase treatment. It seemed that protein depolymerization improved granule fragmentation and rupture, or low molecular protein could interfere between particles of dispersed phase, decreasing the particle adhesion.

Protein addition improved final tridimensional structure of the system, and this improvement was related with the degree of polymerization of soybean protein, the more the proteins were polymerized the more the final viscosity increased. In a system containing whey proteins and corn starch, it has been postulated that it is the entanglement of the protein rather than the swelling of starch which causes differences in the viscosity of the system [24], which also could fit to soybean proteins and starch system.

\section{Rheological properties of the gels}

The frequency sweep plots (Figure 3) showed that the cassava and corn starches with and without SPI presented typical characteristics of a solid-like behavior because the storage modulus was higher than the loss modulus $\left(\mathrm{G}^{\prime}>\mathrm{G}^{\prime \prime}\right)$ throughout the whole range of frequency tested, and the difference tended to increase as the frequency decreased, and both 
moduli were frequency-dependent. In corn starch, $\mathrm{G}^{\prime}$ was independent of the frequency up to frequencies of $0.1 \mathrm{~Hz}$, further on a slightly increased was observed. In opposition $\mathrm{G}^{\prime}$ of cassava starch showed a steady increase with frequency. In both starches, $G^{\prime \prime}$ was highly dependent on the frequency, showing increasing values with the frequency increase. Both cassava and corn starch pastes exhibited a predominant elastic response as it is showed by the loss tangent values (Figure 4). However, cassava starch had higher values of loss tangent than corn starch. Corn starch gel behaved more like a "true gel" when the molecular rearrangements within the network are reduced over the time scales analyzed; while cassava starch gel performed like a "weak gel" suggesting the existence of relaxation processes occurring even at short time scales [25]. Regarding to the macroscopic aspect of the gels, cassava showed a liquid more than solid aspect, and the opposite was observed in corn starch. These results indicated that corn displayed a stronger gel structure and a higher recovering of the stored energy than cassava starch.

The shape of the moduli and loss tangent plots versus frequency was similar for all (enzyme treated and non-treated) corn starch-soybean protein isolate dispersions, where $\mathrm{G}^{\prime}$ exhibited a small dependence at high frequencies, but it was almost independent of frequency below 1-0.1 Hz. On the other hand, the shape of the $G^{\prime}$ and $G^{\prime \prime}$ versus frequency curves for cassava starch gels changed when SPI was included, both $G^{\prime}$ and $G^{\prime \prime}$ exhibited smaller dependence at low frequencies and the differences between moduli were higher when SPI was incorporated. Moreover, the moduli were dramatically shifted to higher values. The "true gel" behavior was accentuated when SPI was included on both cassava and corn pastes

The loss tangent values for cassava starch gels decreased when SPI was included, but the opposite effect was recorded when SPI was included to corn starch, showing the viscoelastic behavior was accentuated when SPI was included on cassava pastes and the opposite effect was produced on corn pastes. Therefore, the effect of SPI on the viscoelastic behavior of starch gels is completely dependent on the starch nature. The same effect was reported when SPI were added to rice flour [11].

The addition of modified proteins on both cassava and corn gels did not affect the shape of the moduli and loss tangents versus frequency curves compare to the gels with non-treated SPI (Figure 3 and 4). However the values of the moduli changed significantly when soybean proteins were enzymatically modified. Table 2 shows the values of the moduli and loss tangent at $1 \mathrm{~Hz}$ of gels at $25^{\circ} \mathrm{C}$. The moduli were shifted to higher values when TGtreated proteins were included on starch pastes, and corn gels showed the highest increment. On the other hand, both moduli were considerably shifted to lower values when AL-treated proteins were included on starch gels. This trend was similar to the final viscosity recorded during the pasting of starch-protein dispersions, indicating that low molecular weight protein could modify the interactions between particles of dispersed phase and decreasing their adhesion, and the properties of the continuous biopolymer matrix (amylose/amylopectin).

When comparing the effects of treated and non-treated protein on gel rheology, the results indicated that the viscoelastic behavior was stressed when TG-treated SPI was included on the gel and the opposite effect was produced by AL-treated SPI.

\section{Microstructure of protein-starchy gels}


The distribution of starch and proteins in the gels was studied by the double-staining method and combining light and fluorescence microscopy. Figure 5 and 6 show micrographs of corn and cassava starches and mixed protein-starch gels. The swollen starch granules were seen in blue (light microscopy) and black (fluorescence microscopy), while the proteins appeared in red. Corn (5 A) and cassava (Figure 6 A) gels exhibited different network structure. Corn gel displayed a continuous phase formed by swollen starch granules pressed against each other, while no-starch granules were identified on cassava gel structure. It appeared that cassava granular structure was complete disintegrated by stirring during pasting processes and let a dispersed phase formed by continuous polymer dispersion (amylose/amylopectin). The rheological properties of such system depend on the properties and the ratio of the components of the continuous phase, the interaction between them and between the dispersed phase and the matrix. Therefore, the dissimilarities of the structures could explain the differences in the rheological behavior of the cassava and corn starches and their mixtures with ISP.

When SPI was included in corn pastes (Figure 5 B), the swollen granules were more separated and the protein appeared to be randomly distributed over the starch dispersion. Protein, but also leached out material, seemed to be localized in the intergranular space between the swollen starch granules. Conversely, SPI-cassava gels showed both protein and starch strands randomly distributed. From these observations, the SPI-starch suspensions could be described as a co-existence of protein-rich zones and starch-rich zones, while corn starch-SPI exhibited the highest separation.

The addition of protease treated SPI drastically changed the structure of the starchy gels. In corn and cassava gels, the protein matrix was barely visible (Figure $5 \mathrm{C}$ and Figure $6 \mathrm{C}$ ). In opposition, the addition of transglutaminase treated SPI to starchy gels intensified the presence of protein agglomerates in the cassava gels (Figure $6 \mathrm{D}$ ), and also favoring the formation of two phases formed by starch and proteins. That effect was not as readily evident in the case of corn starch (Figure 5 D).

Thermal gelation of proteins is a process that requires initial protein unfolding, with exposure of additional hydrophobic residues to the aqueous solvent, and subsequent interaction of the exposed residues to form aggregates [26, 27]. Starch gelation occurs as the hydrated and dispersed starch molecules reassociate, and linear amylose molecules associate more readily than branched amylopectin molecules. Gelatinized starch dispersion may be regarded as a composite material comprised of a dispersed phase (starch granules and granular fragments) in a continuous biopolymer matrix (amylose/amylopectin) [2, 22].

Morris [28] pointed out that because proteins and starches are thermodynamically different biopolymers, their presence together may lead to phase separation, inversion, or mutual interaction. The behavior of biopolymers has significant consequences on the mechanical properties of their mixtures. In an aqueous medium, protein starch system can be thermodynamically compatible (associative, the biopolymers attract each other) or incompatible (seggregative, biopolymers repel each other). If they are thermodynamically incompatible, a two-phase system is obtained in which the two molecules are mostly in separate phases. On the other hand, if they are thermodynamically compatible a homogeneous and stable system, in which the two molecules coexist in a single phase, or a two-phase system where the molecules interact and both are in essentially concentrated phases could be formed $[29,30]$. 
The $\mathrm{pH}$ condition used in this study ( $\mathrm{pH}$ 6.5), increased collective negative charge of soybean protein $(\mathrm{pI} \sim 4.5-5)$, leading to decreased strength of the protein-protein interactions and an increase in the surface of contact with solvent.

The increase of solid-like behavior on SPI-starch structure when gelation takes place could be a consequence of the mutual exclusion of soybean protein and starch from the polymer domain of the other, which increase the effective concentration of both. Since higher excluded volume increases mutual competition between macromolecules for solution space [31], this hypothesis could explain the effect of enzymatically treated-protein addition on solid-like behavior. TG-treated proteins, having higher molecular weight, produce higher exclude volume; and Al-treated proteins, showing lower molecular weight, produce lower exclude volume.

\section{Syneresis}

The water separated from starch gels or starch-containing products is usually viewed unfavorably since it is associated to produce product deterioration and led to consumer rejection. The release of water is produced by the reorganization of starch molecules or retrogradation of starch-based systems during storage [31] and by the interaction between leached amylose and amylopectin chains, which lead to the development of junction zones [32].

Cassava gels did not showed water separation during the storage period ( 7 days), while corn gels released between 11.9 and $25.2 \mathrm{~g}$ of water per $100 \mathrm{~g}$ of total water (Figure 7).

Non-treated SPI and TG-treated SPI decreased the released water due to the high water retention capacity of these proteins. AL-treated proteins dramatically increased gel syneresis, it reached $\sim 25 \%$, even higher than the one observed in corn starch gel without SPI. This behavior could be explained by the loss of water retention capacity as consequence of hydrolysis process and by the negative effect of hydrolyzed protein on gel structure, as was shown by rheological analysis.

\section{CONCLUSION}

Alcalase and transglutaminase modified proteins affected significantly the pasting behavior of both corn and cassava starches. Protein addition increased paste viscosity, and it the extent of that effect was related with the degree of polymerization of soybean protein. Similar trends were found on rheological profile of protein-starch systems, the viscoelastic behavior was stressed when TG-treated SPI was included on the gels and the opposite effect was produced by AL-treated SPI. While cassava (with and without proteins) gels did not show water separation, corn did it, and the hydrolyzing process of proteins dramatically increased gel syneresis.

Protein modification as consequence of transglutaminase and alcalase action modified the pasting, rheological and syneresis behavior, showing that the enzymatic modifications of soybean proteins could overcome the negative changes of the inclusion of soybean protein in starch-based systems. It could be an important tool to increase their application scope in the starch-based foods. 


\section{Acknowledgments}

The authors would like to thank the Consejo Superior de Investigaciones Cientificas (CSIC) and CYTED (PANXTODOS-P106AC0301) for financial support. P.D. Ribotta would like to thank Conselleria de Educacio I Ciencia of the Comunidad Valenciana for his postdoctoral grant.

\section{References}

[1] J. G. Endres: Soy Protein Products Characteristics, Nutritional Aspects and Utilization, AOCS Press, Illinois, 2001.

[2] P. D. Ribotta, A. Colombo, A. E. León, M .C. Añón: Effects of soybean protein on physical and rheological properties of wheat starch. Starch/Starke 2007, 59, 614-623.

[3] K. M. Abdo, K. W. King: Enzymatic Modification of the Extractability of Protein from Soybeans, Glycine max. J. Agric. Food Chem. 1967, 15, 83-89.

[4] G. MacLeod,J. Ames: Soy Flavor and its Improvement. Critical Reviews in Food Science and Nutrition 1988, 27, 218-402.

[5] M. J. Periago, M. L. Vidal, G. Ros: Influence of enzymatic treatment on the nutritional and functional properties of pea flour. Food Chem. 1998, 63, 71-78.

[6] D. Doucet, D. E. Otter, S. F. Gauthier, F. A. Foegeding: Enzyme-induced gelation of extensively hydrolyzed whey proteins by alcalase: Peptide identification and determination of enzyme specificity. J. Agric. Food Chem. 2003, 51, 6300-6308.

[7] J. Adler-Nissen: A review of food protein hydrolysis, in Enzymic hydrolysis of food proteins (Ed. J. Adler-Nissen) Elsevier Applied Science Publishers, New York, 1986.

[8] M. Motoki, K. Seguro: Transglutaminase and its use for food processing. Trends Food Sci. Technol. 1998, 9, 204-210.

[9] M. Nonaka, H. Tanaka, A. Okiyama, M. Motoki, H. Ando, K. Urneda, A. Matsura: Polymerisation of several proteins by $\mathrm{Ca} 2+$, independent transglutaminase derived from micro-organisms. Agricultural and Biological Chemistry 1989, 53, 2619-2623.

[10] M. Motoki, N. Nio, K. Takinami: Functional properties of food proteins polymerized by transglutaminase. Agricultural and Biological Chemistry 1984, 48, 1257-1261.

[11] C. Marco, C. M. Rosell: Modification of rice proteins functionality by crosslinking with different protein isolates. J. Food Eng. 2008, 84, 132-139.

[12] E. E. Babiker: Effect of transglutaminase treatment on the functional properties of native and chymotrypsin-digested soybean protein. Food Chem., 2000, 70, 139-145.

[13] H. Babin, E. Dickinson: Influence of transglutaminase treatment on the thermoreversible gelation of gelatin. Food Hydrocolloids 2001, 15, 271-276.

[14] D. J. Walsh, D. Cleary, E. McCarthy, S. Murphy, R. J. FitzGerald: Modification of the nitrogen solubility properties of soybean protein isolate following proteolysis and transglutaminase cross-linking. Food Research International 2003, 36, 677-683. 
[15] C-H. Tang, H. Wu, H-P. Yu, L. Li, Z. Chen, X-Q. Yang : Coagulation and gelation of soybean protein isolates induced by microbial transglutaminase. J. Food Biochemistry 2006, 30, 35-55.

[16] C. Marco, C. M. Rosell: Breadmaking performance of protein enriched gluten free breads. Eur. Food Res. Technol. 2008, 227, 1205-1213.

[17] X. Kong, H. Zhou, H. Qian : Enzymatic preparation and functional properties of wheat gluten hydrolysates. Food Chem. 2007, 101, 615-20.

[18] C. Marco,G. Pérez, A. León, C. M. Rosell: Effect of microbial transglutaminase on the protein electrophoretic pattern of rice, soybean and their blends. Cereal Chem. 2008, 85, 59-64.

[19] E. L. Arrese, D. A. Sorgentini, J. R.Wagner, M. C. Añon: Electrophoretic, solubility, and functional-properties of commercial soy protein isolates. J. Agric. Food Chem. 1991, 39:1029-1032.

[20] P. K. Goel, R. S. Singhal, P. R. Kulkarni: Studies on interactions of corn starch with casein and casein hydrolysates. Food Chem. 1999, 64, 383-389.

[21] G. R. Ziegler, E. A. Foegeding: The gelation of proteins. Advanced Food Nutrition Research 1990, 34, 203-298.

[22] A. Eliasson, M. Gudmundsson: Starch: Physicochemical and functional aspects, in Carbohydrates in Food (Ed. A. Eliasson) Marcel Dekker, New York, 1996.

[23] H. S. Lim, G. Narsimhan: Pasting and rheological behavior of soy protein-based pudding. LWT-Food Sci. Technol. 2006, 39, 343-349.

[24] P. Pogaku, C. E. Seng, L. Boonbeng, A. Reddy Kallu: Whey Protein Isolate-Starch System- A Critical Review. Int. J. Food Engineering 2007, 3, 1-28.

[25] J. A. Lopes da Silva, M. A. Rao: Rheological Behavior of Food Gel Systems, In Rheology of Fluid and Semisolid Foods (Ed. M.A. Rao) A Chapman \& Hall Food Science Book, USA, 1999.

[26] A. H. Clark, G. M. Kavanagh, S. B. Ross-Murphy: Globular protein gelation-theory and experiment. Food Hydrocollids 2001, 15, 383-400

[27] M. C. Nunes, A. Raymundo, I. Sousa: Gelled vegetable desserts containing pea protein, $\kappa$-carrageenan and starch. Eur. Food Res. Technol. 2006, 222, 622-628.

[28] V. J. Morris: Starch Gelation and retrogradation. Trends Food Sci. Technol. 1990, 1, 26.

[29] M. A. Rao: Rheology of food gums and starch dispersion, in Rheology of Fluid and Semisolid Foods (Ed. M. A. Rao) A Chapman \& Hall Food Science Book, USA, 1999.

[30] V. Tolstoguzov: Some thermodynamic considerations in food formulation. Food Hydrocolloids 2003, 17, 1-23.

[31] G. H. Zheng, F. W. Sosulski: Determination of water separation from cooked starch and flour pastes after refrigeration and freeze-thaw. J. Food Sci. 1998, 63, 134-139. 
[32] C. Perera, R. Hoover: Influence of hydroxypropylation on the retrogradation properties of native, defatted and heat -moisture treated potato starches. Food Chem. 1999, 64, 361-375. 


\section{FIGURE CAPTIONS}

Figure 1. Effect of transglutaminase and alcalase modification on electrophoretic protein profile. Lanes: Molecular weight standard (St), not modified SPI (1), TG-treated SPI (2), Al-treated SPI (3).

Figure 2. Effect of soybean proteins on corn and cassava starch pasting properties. C: Corn starch. T: cassava starch. SPI: soybean protein isolate, SPI+TG: TG treated SPI, SPI+AL: protease treated SPI.

Figure 3. $\mathrm{G}^{\prime}$ and $\mathrm{G}^{\prime \prime}$ as a function of frequency. A: Corn starch. B: cassava starch. Starch $\left(\mathrm{G}^{\prime}(\bullet), \mathrm{G}^{\prime \prime}(\diamond)\right)$, starch+SPI $\left(\mathrm{G}^{\prime}(\boldsymbol{\bullet}), \mathrm{G}^{\prime \prime}(\square)\right)$, starch + SPI + TG $\left(\mathrm{G}^{\prime}(\boldsymbol{\Delta}), \mathrm{G}^{\prime \prime}(\triangle)\right)$, and starch $+\mathrm{SPI}+\mathrm{AL}\left(\mathrm{G}^{\prime}(\bullet), \mathrm{G}^{\prime \prime}(\circ)\right)$.

Figure 4. Loss tangent as a function of frequency. A: Corn starch. B: cassava starch. Starch $(\diamond), \operatorname{starch}+$ SPI $(\bullet)$, starch + SPI + TG $(\boldsymbol{\Delta})$, and starch+SPI+AL $(\bullet)$.

Figura 5. The light (left) and fluorescence (right) micrographs of corn starch and mixed protein-corn starch gels. A: Corn starch. B: Corn starch+SPI, C: corn starch+SPI+AL, and D: corn starch+SPI+TG.

Figure 6. The light (left) and fluorescence (right) micrographs of cassava starch and mixed protein-cassava starch gels. A: cassava starch. B: cassava starch+SPI, C: cassava starch + SPI+AL, and D: cassava starch + SPI+TG.

Figure 7. Effect of soybean protein on corn gel syneresis. C: corn gel, C-SPI: soybean protein isolate-corn starch gel, 2: SPI+TG: TG treated SPI-corn starch gel, and SPI+AL: alcalase treated SPI-corn starch gel. 
Table 1. Effect of soybean protein isolates (SPI) treated with protease (AL) or transglutaminase (TG) on pasting properties of corn (C) and cassava (T) starches.

\begin{tabular}{lcccrc}
\hline & \multicolumn{1}{c}{$\mathbf{P T}\left[{ }^{\circ} \mathbf{C}\right]$} & \multicolumn{1}{c}{ PV [cP] } & \multicolumn{1}{c}{ FV [cP] } & \multicolumn{1}{c}{ BD [cP] } & \multicolumn{1}{c}{ SB [cP] } \\
\hline C & $90.0 \pm 2.8$ & $373 \pm 1$ & $299 \pm 12$ & $112 \pm 1$ & $38 \pm 12$ \\
C-SPI & $77.9 \pm 1.2$ & $487 \pm 7$ & $969 \pm 25$ & $46 \pm 4$ & $530 \pm 14$ \\
C-SPI+AL & $67.3 \pm 4.5$ & $664 \pm 20$ & $758 \pm 13$ & $207 \pm 8$ & $301 \pm 25$ \\
C-SPI+TG & $74.3 \pm 1.7$ & $769 \pm 3$ & $1307 \pm 25$ & $81 \pm 11$ & $618 \pm 17$ \\
\hline T & $69.8 \pm 0.4$ & $635 \pm 20$ & $697 \pm 5$ & $182 \pm 19$ & $243 \pm 6$ \\
T-SPI & $72.7 \pm 0.0$ & $1292 \pm 14$ & $1660 \pm 17$ & $299 \pm 16$ & $666 \pm 15$ \\
T-SPI+AL & $70.7 \pm 0.5$ & $1461 \pm 6$ & $989 \pm 11$ & $832 \pm 18$ & $360 \pm 23$ \\
T-SPI+TG & $70.7 \pm 0.4$ & $1770 \pm 11$ & $1791 \pm 1$ & $641 \pm 16$ & $662 \pm 6$ \\
\hline
\end{tabular}

PT: Pasting temperature, PV: peak viscosity, FV: final viscosity, BD: breakdown, and SB: setback.

Table 2. Effect of soybean protein isolates (SPI) treated with protease (AL) or transglutaminase (TG) on rheological properties of corn (C) and cassava (T) starch gels.

\begin{tabular}{lllllll}
\hline & \multicolumn{2}{l}{ G $^{\prime}$ [Pa] } & \multicolumn{2}{l}{ G' $^{\prime \prime}$ [Pa] } & \multicolumn{2}{l}{ Loss tangent } \\
\hline C & 74.7 & \pm 8.0 & 9.0 & \pm 0.4 & 0.122 & \pm 0.016 \\
C-SPI & 73.8 & \pm 3.1 & 13.9 & \pm 1.1 & 0.188 & \pm 0.007 \\
C-SPI+AL & 67.5 & \pm 2.7 & 11.1 & \pm 0.3 & 0.165 & \pm 0.005 \\
C-SPI+TG & 107.6 & \pm 5.4 & 18.2 & \pm 0.9 & 0.169 & \pm 0.009 \\
\hline T & 10.2 & \pm 0.2 & 4.0 & \pm 0.1 & 0.390 & \pm 0.007 \\
T-SPI & 56.5 & \pm 5.5 & 10.6 & \pm 1.0 & 0.188 & \pm 0.007 \\
T-SPI+AL & 34.0 & \pm 1.5 & 6.2 & \pm 0.3 & 0.184 & \pm 0.006 \\
T-SPI+TG & 58.1 & \pm 3.9 & 12.0 & \pm 0.2 & 0.207 & \pm 0.010 \\
\hline
\end{tabular}

$\mathrm{G}^{\prime}$ : storage modulus, $\mathrm{G}^{\prime \prime}$ : loss modulus. Measurements at $1 \mathrm{~Hz}$. 